\title{
SOIL MOISTURE MODEL WITH MULTI ANGLE AND MULTI POLARISATION RISAT-1 DATA
}

\author{
S. S. Rao ${ }^{a}$, D. K. Sahadevan ${ }^{a}$, M. R. Wadodkar ${ }^{\mathrm{a}}$, M.S.S. Nagaraju ${ }^{\mathrm{b}}$, S. Chattaraj ${ }^{\mathrm{c}}$, W. Joseph ${ }^{\mathrm{c}}$, P. Rajankar ${ }^{\mathrm{d}}$, T. Sengupta ${ }^{\mathrm{e}}$, M. V. \\ Venugopalan ${ }^{\mathrm{e}}$, S. N. Das ${ }^{\mathrm{f}}$, A. K. Joshi ${ }^{\mathrm{b}}$, J. R. Sharma ${ }^{\mathrm{a}}$, E. Amminedu ${ }^{\mathrm{g}}$ \\ ${ }^{a}$ Regional Centre, National Remote Sensing Centre, Balanagar, Hyderabad, India, 500037 - ssrao@nrsc.gov.in, (sdineshkumar1987, \\ milindrw, jrsharma50)@gmail.com \\ ${ }^{\mathrm{b}}$ Regional Remote Sensing Centre - Central, Amravati Road, Nagpur, India, 440010 - (akjoshingp, \\ prashantrajankar)@rediffmail.com, mssnagaraju@yahoo.com, \\ ${ }^{c}$ National Bureau of Soil Survey \& Land Use Planning, Amravati Road, Nagpur, India, 440033 - tutushagun@rediffmail.com, \\ joshphilo@gmail.com \\ ${ }^{\mathrm{d}}$ Soil and Land Use Survey of India, Nagpur, India, 4400130 - prashantrajankar@rediffmail.com \\ ${ }^{\mathrm{e}}$ Maharashtra Remote Sensing Applications Centre, Nagpur, India, 440011 - mvvenugopalan@gmail.com \\ ${ }^{\mathrm{f}}$ Central Institute of Cotton Research, Nagpur, India, 440010 - subratondas@rediffmail.com \\ ${ }^{g}$ Dept of Geo Enng, AU College of Engg, Visakhapatnam, India, 530003 - eamminedu@gmail.com
}

KEY WORDS: Soil Moisture, RISAT-1, Multi-Polarisation, Multi-Angle, Dielectric Constant, Backscatter, RISAT Utilisation Programme

\begin{abstract}
:
Multi dimensional data (multi frequency, incident angle and polarisation) measurements of $\sigma_{0}$ provided better estimates of soil moisture over those derived from single. This particular paper explains a new methodology for soil moisture estimation with the use of multi angle and multi polarisation RISAT-1 data. The roughness component was derived by correlating root mean square height with the differences of cross polarisation and like polarisation backscatter values $\left(\sigma_{\mathrm{HV}}-\sigma_{\mathrm{HH}}\right)$ and differences of low and high incidence backscatter values ( $\sigma_{\mathrm{HH}}$ high $(\theta)-\sigma_{\mathrm{HH}}$ Low). The derived roughness was inputted to the modified dubois model (MDM). The results show both the $\sigma_{H V}-\sigma_{H H} \& \sigma_{H H}$ high $(\theta)-\sigma_{H H}$ Low are sensitive to roughness. The derived soil moisture using the MDM model is shows reasonable correlation with ground soil moisture.
\end{abstract}

\section{INTRODUCTION}

The physical models for soil moisture estimation give the site independent results. However physical models involve numerous parameters in it hence often it's difficult to reverse the models. The constrain in the model environment is also a difficult issue, for an example the small perturbation model (SPM), geometrical optic model (GOM) are used for smooth surfaces physical, where as optic model (POM) used in rough surface environment. Thus specific model for specific roughness environment hampers the applicability of these models in the practical situations.

On the other hand the empirical models need a huge amount of ground data regarding target parameters (ie: roughness, soil moisture, vegetation...etc) corresponds to sensor parameters to model and these model are mostly confined to particular site circumstances and can't apply to new study area.

The semi empirical models are compromised between theoretical and physical models by applying some approximation and simplifications while retaining physical meaning. The semi empirical model developed by $\mathrm{Oh}$ et al. 1992 and Dubois model et al., 1995 and Water cloud model (Attema, E.W.P. and Ulaby, F.T. 1978) are the notable semi empirical models. Estimation of Dielectric constant with Modified Dubois Model (MDM) developed by Sahebi, M. R., \& Angles, J. (2010) shows good agreement with the ground data with mean error of 2.46 followed by OM and GOM. The study also explains MDM is more exact for estimation of dielectric constant than RMS height. The surface roughness strongly influences the strength of radar return and at times the effect of surface roughness becomes comparable to or even more than the effect of soil moisture (Srivastava et al. 2006). Thus considering roughness in the model is an important issue. In this study roughness was derived with two methods, i.e. i) correlating $\sigma \mathrm{HV}-\sigma \mathrm{HV}$ with ground RMS height ii) $\sigma \mathrm{HH}$ high $(\theta)-\sigma$ HH Low $(\theta)$. This developed method is more simple and realistic for the estimation of soil moisture.

\section{STUDY AREA}

The study area is located in Vidarbha region of Maharashtra, India centred at $21^{\circ} 07^{\prime} 00^{\prime \prime} \mathrm{N} / 78^{\circ} 55^{\prime} 00^{\prime \prime}$ E. The majority of the area comes under rainfed with major crops of cotton, soya beans and gram. The study area temperature ranges from $48^{\circ} \mathrm{C}$ in summer and $7^{\circ} \mathrm{C}$ in winter. The annual rainfall is around $1100 \mathrm{~mm}$ with south west monsoon (July to October) contribution almost $80 \%$ to this region. Hence usually cultivation starts in mid July and ends in starting of November. The topography is ranging from $280 \mathrm{~m}$ to $340 \mathrm{~m}$. The study area is mostly covered under heavy clay soil. Due to the presence of heavy clay scenario cotton is more preferable crop. Unfortunately making model in such heavy clay condition for soil moisture is a very tedious job. 
ISPRS Annals of the Photogrammetry, Remote Sensing and Spatial Information Sciences, Volume II-8, 2014

ISPRS Technical Commission VIII Symposium, 09 - 12 December 2014, Hyderabad, India

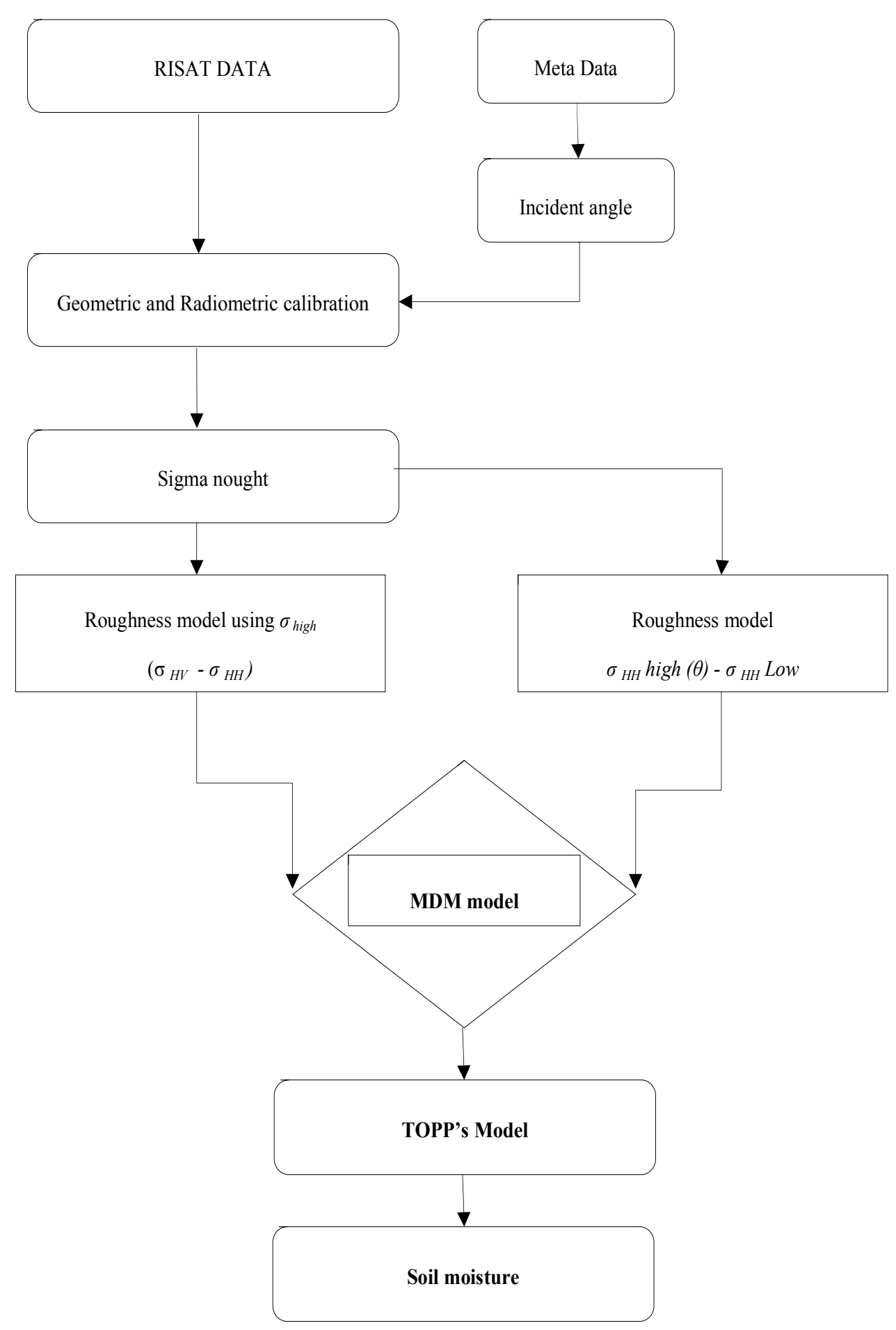

Figure1. Procedure followed in this research 
ISPRS Annals of the Photogrammetry, Remote Sensing and Spatial Information Sciences, Volume II-8, 2014 ISPRS Technical Commission VIII Symposium, 09 - 12 December 2014, Hyderabad, India

\begin{tabular}{|c|c|c|c|c|c|c|}
\hline S. No. & Date & Satellite & Imaging Mode & Polarization & Center Incident angle & Resolution (m) \\
\hline \multirow{2}{*}{1} & $04 / 07 / 2013$ & RISAT-1 & CRS & HH,HV & 22.65 & 36 \\
\cline { 2 - 7 } & $06 / 07 / 2013$ & RISAT-1 & CRS & HH,HV & 48.71 & 36 \\
\hline \multirow{2}{*}{2} & $25 / 10 / 2013$ & RISAT-1 & CRS & HH,HV & 24.36 & 36 \\
\cline { 2 - 7 } & $26 / 10 / 2013$ & RISAT-1 & CRS & HH,HV & 41.43 & 36 \\
\hline
\end{tabular}

Table.1 details of acquired RISAT-1 data

\section{DATA AND METHODS}

The RISAT-1 data Course Resolution Data (CRS) were acquired in the ground range. The details of acquired RISAT1 data with information of Imaging mode, polarisation, incident angle, resolution is shown in table 1 .

The geometric correction was done using Carto-DEM as a part of pre-processing. The geometric accuracy of the RISAT-1 data was verified with geo-corrected LISS-IV data and Radarsat-2. The acquired scenes had geometric error of 4-5 pixels in common. Geometric correction was performed using Radarsat-2 data as a base image and accuracy was maintained within a pixel. The incident angle was generated from the grid file that was given along with data. In grid file latitude and longitude and incident angle column were used for incident angle generation. The available incident angle in gridded point format was interpolated and incident angle image generated with the same pixel size of RISAT-1 data.

The back scattering coefficient calibrated using the equation 1 below:

$$
\begin{aligned}
\sigma_{o}(d B)=20 \log _{10}( & \left(D N_{p}\right)-K_{d B} \\
& +10 \log _{10}\left(\text { si i }_{p} / \sin \left(I_{\text {center }}\right)\right)
\end{aligned}
$$

Radiometric calibration requires four inputs

$D N p$ : Digital number, (Image pixel value)

$K_{d B}$ : Calibration Constant in $\mathrm{dB}$, Available in product.xml / Meta data file

$i_{p}$ : Incident angle for pixel position $\mathrm{p}$, generated from grid file

$I_{\text {center }}$ : Incident angle at the scene center, available in BAND_META file in Incidence Angle column

The Sigma nought image generated using the formula given in Eqn.1. It was found that there are some anomalies i.e.: very high and low value of sigma nought observed. Hence all images were filtered using a median filter with $3 * 3$ window size. The median filter was selected based on M.M. Rahman et al.2008, R. van der Velde et al.2012 studies. The low window size $3 * 3$ was chosen since the spatial resolution of CRS data is $36 \mathrm{~m}$ and soil moisture may vary within the large window size. However roughness model derived without any filtering since roughness is a highly variable phenomenon than soil moisture and filter may reduce the sharpness of data (thus loss of detail about roughness). The methodology is followed as shown in flow sort (figure.1).

\section{FIELD DATA CAMPAIGNS}

A total of 50 fields sites were selected and following details were taken from the field i.e. three soil samples, a ground roughness graph with $1 \mathrm{~m}$ length, tilling direction, crop type, and crop height. Soil moisture and roughness details were collected synchronous with the low incident angle data pass. The roughness measurement was done by drawing a graph across tilling direction and it was examined at $1 \mathrm{~cm}$ intervals over $1 \mathrm{~m}$ in total for RMS calculation.

Root mean square height was calculated using equation 2 below:

$$
S=\sqrt{\frac{\sum_{i=0}^{n}\left(Z_{i}-\bar{Z}\right)^{2}}{n-1}}
$$

Here, $Z_{i}$ denotes the height of the point on $\mathrm{X}_{\mathrm{I}}$, refers the mean height, $n$ is the total number of points. In the study area the RMS height varied from the $0.25 \mathrm{~cm}$ to $3 \mathrm{~cm}$.

The three soil samples per site were collected in $0-5 \mathrm{~cm}$ depth of soil surface. The bulk density values were analysed for each soil sample. The soil samples were dried in oven at $105^{\circ} \mathrm{c}$ for 24 hours getting gravimetric soil moisture value, which is converted to volumetric soil moisture by the multiplying bulk density.

\section{MODIFIED DUBOIS MODEL (MDM) FOR RISAT-1}

Modified Dubois model developed by Sahebi, M. R., \& Angles, J. (2010) has the advantage of working condition of $\theta$ $=20^{\circ}-50^{\circ}, 1 \mathrm{~cm}<\mathrm{s}<6 \mathrm{~cm}$ and $14 \%<\mathrm{mv}<32 \%$. Thus we could able to get rid of one of the drawback of original Dubois model that requires incident angle should be more than $30^{\circ}$. This is very important point since the sensitivity of sigma nought against the soil moisture is inversely proportional to the incident angle.

$\sigma^{o} h h=10^{-367} \frac{\cos ^{5} \theta}{\sin \frac{\gamma}{8}} \times 10^{\alpha 11} 2 \varepsilon \tan \theta(k s \sin \theta)^{188} \not^{\sigma \sigma}$

The $\theta$ represents the incidence angle, $\varepsilon$ is the real part of dielectric constant, ' $\mathrm{k}$ ' is the wave number $(2 \pi / \lambda)$, and $\mathrm{s}$ is the root mean square height represents vertical height variation in the terrain, where the incidence angle $(\theta)$ is 
calculated from metadata file, wavelength $(\lambda=5.3)$, the unknown parameter RMS height's' will be replaced by roughness model derived by following section.

\section{SURFACE ROUGHNESS MODEL DERIVATION}

Surface roughness is described as the surface height variance compared to a smooth reference surface. Surface roughness and soil moisture are two important factors that affect SAR backscatter from bare agricultural fields (Ulaby et al. 1978) hence accurate surface roughness parameter is essential for retrieving soil moisture from radar backscatter. Roughness can be modelled with multi incidence angle or multi polarization approach. The ground surface roughness was measured using a graph and RMS heights were calculated as explained in previous section. The ratio polarisation $\sigma \mathrm{HV}$ $\sigma \mathrm{HH}$ is found to be sensitive to roughness (S.Srinivasa Rao et., 2013). The depolarization ratio (VH to VV polarization) was found to be very sensitive to soil surface roughness (Srivastava et al., 2008; Oh et.al., 1992). Hence the roughness model was derived using $\sigma \mathrm{HV}-\sigma \mathrm{HH} \& \sigma \mathrm{HH}$ $\operatorname{high}(\theta)-\sigma$ HH Low.

\section{ROUGHNESS MODEL BY DUAL}

\section{POLARIMETRIC APPROACH WITH $\Theta_{\text {HIGH }}$ DATA}

The ground measured RMS height of $06^{\text {th }}$ July 2013 measurements were plotted against the $\sigma \mathrm{HV}-\sigma \mathrm{HH}$ of high incidence angle data of same date and its correlated well (Figure.2) with $\mathrm{r}^{2}$ value of 0.8158 .

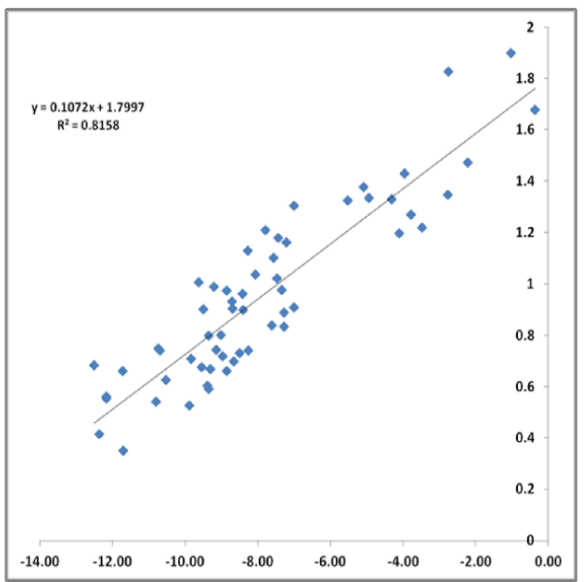

Figure 2. Roughness model by dual polarimetric approach with $\theta_{\text {high }}$ data RMS height (Y axis) against $\sigma_{H V}-\sigma_{H H}$ (X axis)

\section{ROUGHNESS MODEL BY DUAL INCIDENCE ANGLE APPROACH $\Theta_{\text {HIGH }} \& \Theta_{\text {LOW }}$}

The ground measured RMS height of July 2013 measurements were plotted against the $\sigma \mathrm{HH}$ high $(\theta)-\sigma \mathrm{HH}$ Low $(\theta)$ of same date and its correlated well (Figure.3) with $r^{2}$ value of 0.811

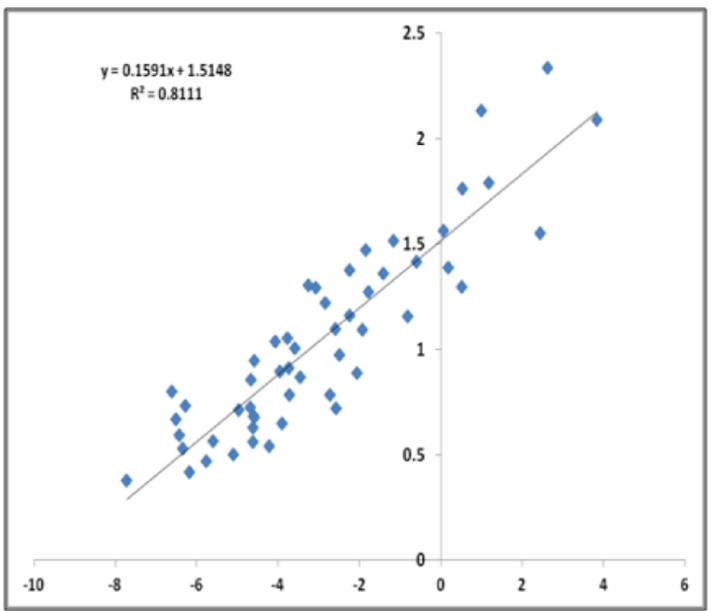

Figure 3. RMS (Y axis) against $\sigma_{H H}$ high $(\theta)-\sigma_{H H}$ Low $(\theta)$ (X axis)

\section{TOPP'S MODEL}

The soil moisture can be derived from the dielectric constant using (Topp et al.,1980) model. This model has been used by many researchers effectively for retrieving soil moisture (Song et al.,2010). This model doesn't require any prior knowledge about the soil texture, needs only the dielectric constant of the soil. The soil moisture $\theta \mathrm{v}$ related with the dielectric constant $(\varepsilon)$ as follows

$$
\begin{aligned}
\theta_{v}=-5.3 \times 10^{-2} & +2.92 \times 10^{2} \varepsilon-5.5 \times 10^{-4} \varepsilon^{2}+4.3 \\
& \times 10^{-6} \varepsilon^{3}
\end{aligned}
$$

\section{SOIL MOISTURE FROM MDM USING $\sigma^{0} \mathrm{HH}$ $\operatorname{LOW}(\Theta)\left(\operatorname{RMS~FROM} \sigma_{H V}-\sigma_{H H}\right)$}

Then RMS height derived from $\sigma \mathrm{HV}-\sigma \mathrm{HH}$ were subtituted to MDM model to retrieve soil moisture. The retrieved soil moisture were plotted against the ground soil moisture for validation. The $\mathrm{r}^{2}$ of $0.75 \& 0.59$ was obtained in the $04^{\text {th }}$ July 2014 and $25^{\text {th }}$ October 2014 respectively (Figure $4 \& 5$ ). The statistical results are shown in table 2 . 
ISPRS Annals of the Photogrammetry, Remote Sensing and Spatial Information Sciences, Volume II-8, 2014

ISPRS Technical Commission VIII Symposium, 09 - 12 December 2014, Hyderabad, India

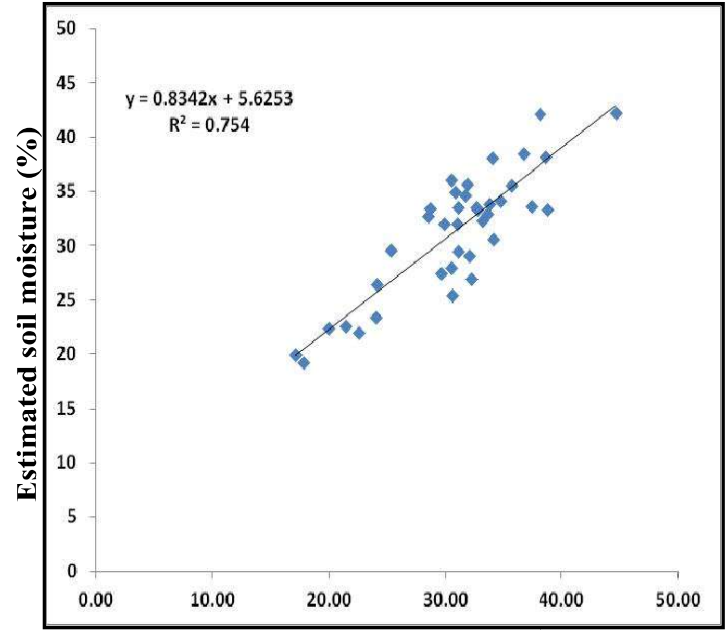

Measured soil moisture (\%) $-04^{\text {th }} \mathrm{July}, 2013$

Figure 4. Estimated SM against Measured SM

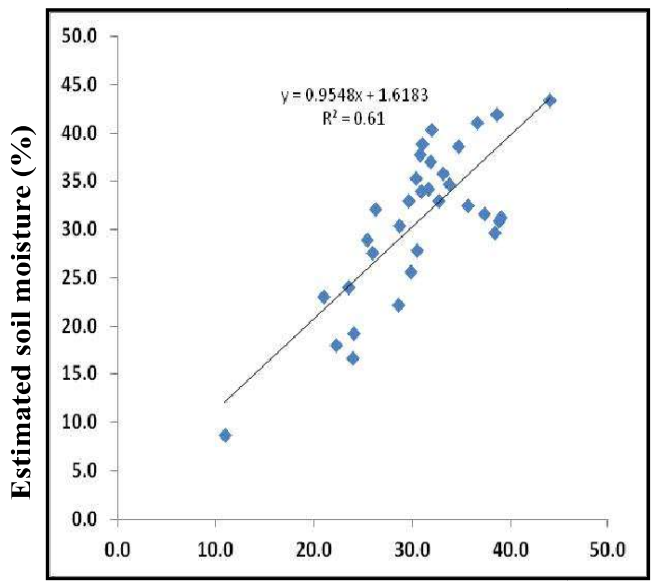

Measured soil moisture (\%) $-04^{\text {th }} \mathrm{July}, 2013$

Figure.6 Estimated SM against Measured SM

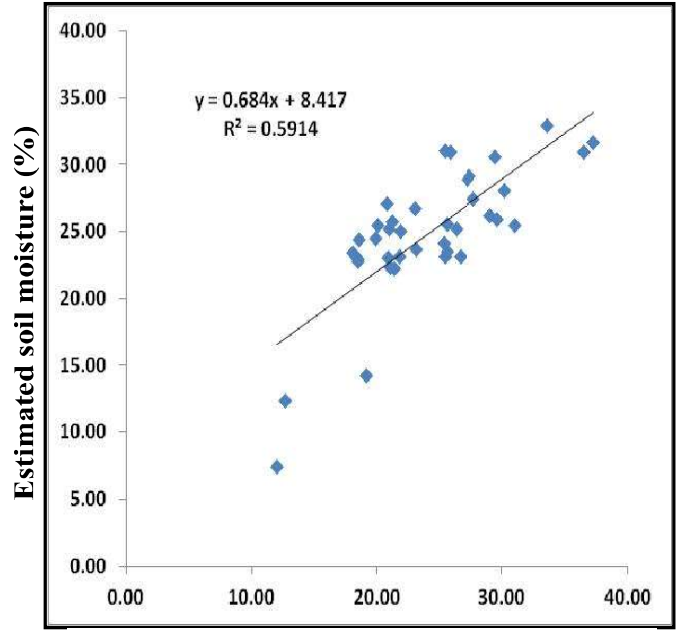

Measured soil moisture (\%) $-25^{\text {th }}$ Oct, 2013

Figure 5. Estimated SM against measured SM

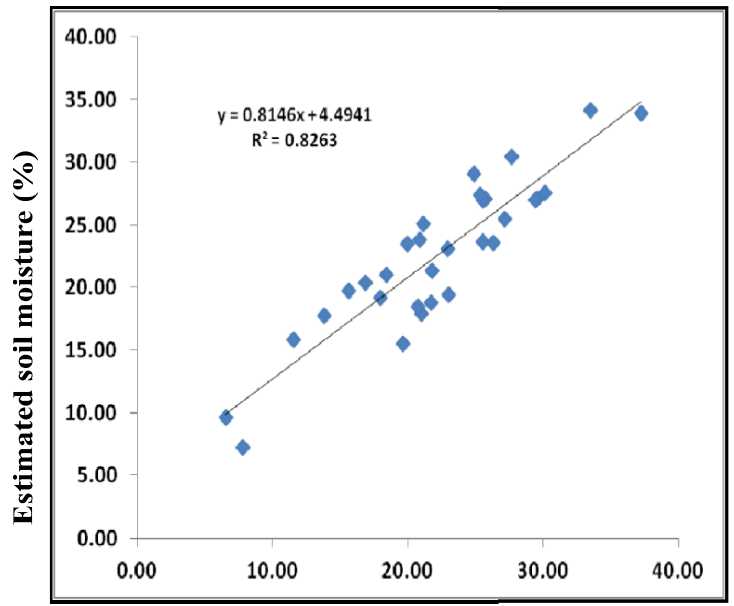

Measured soil moisture (\%) $-25^{\text {th }}$ Oct, 2013

Figure.7 Estimated SM against measured SM

\begin{tabular}{|c|c|c|c|}
\hline Date & Coefficient of determination $\left(\mathrm{r}^{2}\right)$ & RMSE & Number of measurements \\
\hline $04^{\text {th }}$ July 2013 & 0.75 & 2.87 & 38 \\
\hline $25^{\text {th }}$ Oct 2013 & 0.59 & 3.20 & 38 \\
\hline
\end{tabular}

Table 2. Soil moisture from MDM using $\sigma^{0} \mathrm{HH} \operatorname{Low}(\theta)\left(\mathrm{RMS}\right.$ from $\left.\sigma_{H V}-\sigma_{H H}\right)$

\begin{tabular}{|c|c|c|c|}
\hline Date & Coefficient of determination $\left(\mathrm{r}^{2}\right)$ & RMSE & Number of measurements \\
\hline $04^{\text {th }}$ July 2013 & 0.61 & 4.99 & 33 \\
\hline $25^{\text {th }}$ Oct 2013 & 0.82 & 2.60 & 33 \\
\hline
\end{tabular}

Table 3. Soil moisture from MDM using $\sigma^{0} \mathrm{HH} \operatorname{Low}(\theta)\left(\operatorname{RMS}\right.$ from $\sigma^{0} \mathrm{HH}$ high $(\theta)-\sigma^{0} \mathrm{HH}$ Low $\left.(\theta)\right)$ 


\section{SOIL MOISTURE FROM MDM USING $\sigma{ }^{0} \mathrm{HH}$ LOW $(\Theta)\left(\right.$ RMS $\left.\sigma_{H H} H I G H(\Theta)-\sigma_{H H} L O W\right)$}

Then RMS height derived from $\sigma_{H H}$ high $(\theta)-\sigma_{H H}$ Low $(\theta)$ were subtituted to MDM model to retrieve soil moisture. The retrieved soil moisture were plotted against the ground soil moisture for validation. The $\mathrm{r}^{2}$ of $0.61 \& 0.82$ was obtained in the $04^{\text {th }}$ July 2014 and $25^{\text {th }}$ October 2014 respectively (Figure 6 \& 7). The statisitical results are shown in table 3.

The first data $\left(04^{\text {th }}\right.$ July 2013$)$ was acquired when the cultivation started, and the second data $\left(25^{\text {th }}\right.$ October 2013) was acquired when the cultivation was in ending stage (matured crop condition). From the ground inference it was known that the in July the cultivation was just started and hence there is very less vegetation influence in the data but there is greater influence from the roughness apart from soil moisture. The first method $\sigma_{H V}-\sigma_{H H}$ works well even the roughness influence is high. But the performance of this method becomes poor once vegetation grows. The reverse of this phenomenon observed in the second method i.e. High correlation was observed in the $25^{\text {th }}$ October 2013, when field was almost covered with vegetation. This is due to the fact that high incidence angle is sensitive to vegetation (Gherboudj et al., 2011), thus incorporating $\sigma_{\mathrm{HH}}$ high $(\theta)$ is more suitable for retrieval of soil moisture when ground is covered with the vegetation.

\section{CONCLUSIONS}

The developed method here is more simple and realistic for the estimation of soil moisture. The roughness component was derived by correlating root mean square height with the differences of cross polarisation and like polarisation backscatter values and differences of low and high incidence backscatter values. The derived roughness was inputted to the modified Dubois model (MDM). The results show both the backscatter values and the differences of low and high incidence backscatter values are sensitive to roughness. The derived soil moisture using the MDM model shows reasonable correlation with ground soil moisture.

\section{ACKNOWLEDGMENTS}

This work was performed under RISAT Utilization Project funded by Indian Space Research Organization (ISRO). The project team wants to thank Dr. V. K Dadhwal, Director, NRSC for his encouragements and support. We express our thanks to the Dr. Manab Chakraborthy, Project Director, RISAT-UP for his help throughout this project. The project team thank D. S Mohekar - NBSS, Nitin Tendulkar, CICR, Siva Prasad Reddy - JRF RRSC/NRSC, I Ramteke, S VermaMRSAC, S R Potpite, J.P Suman, Arun Kumar Rajwar SLUSI for their help in soil sample analysis, ground truth collection and process. We also thank Directors of National Bureau Soil Science / Land Use Planning, Nagpur, Central Institute Cotton Research (CICR), Nagpur, Maharashtra Remote Sensing Applications Centre (MRSAC) and Soil and Land Use Survey of India (SLUSI) for their support in throughout the project.

\section{REFERENCES}

Attema, E.W.P. \& Ulaby, F.T., 1978. Vegetation modelled as a water cloud. Radio Science, 13(2), pp. 57-64.
Dubois, P. C., Van Zyl, J., \& Engman, T. 1999. Measuring soil moisture with imaging radars. Geoscience and Remote Sensing, IEEE Transactions 33(4), pp. 915-926.

Gherboudj, I., Magagi, R., Berg, A. A., \& Toth, B. (2011). Soil moisture retrieval over agricultural fields from multipolarized and multi-angular RADARSAT-2 SAR data. Remote Sensing of Environment, 115(1), 33-43.

M.M. Rahman et al. 2008. Remote Sensing of Environment 112, pp. 391-402.

Oh, Y., Sarabandi, K., \& Ulaby, F. T. 1992. An empirical model and an inversion technique for radar scattering from bare soil surfaces. Geoscience and Remote Sensing, IEEE Transactions on, 30(2), pp. 370-381.

Oh, Y., Sarabandi, K., \& Ulaby, F. T. 1992. An empirical model and an inversion technique for radar scattering from bare soil surfaces. Geoscience and Remote Sensing, IEEE Transactions, 30(2), pp. 370-381.

R. van der Velde et al., 2012. Remote Sensing of Environment 120, pp. 175-187.

Srivastava , H.S., Patel,P., \& Navalgund,R.R., 2006. How far SAR has fulfilled its expectation for soil moisture retrieval? Microwave Remote Sensing of Atmosphere and Environment-II, AE107, Asia Pacific Remote Sensing Symposium, Goa, India. SPIE Digital Library, Vol. 6410, Paper No. 641001, pp. 1-12.( 13-17 Nov.2006).

S. Srinivasa rao, et al. 2013. Modified Dubois Model for Estimating Soil Moisture with Dual Polarized SAR Data. Journal of the Indian Society of Remote Sensing 41.4, pp. 865-872.

Sahebi, M. R. \& Angles, J., 2010. An inversion method based on multi-angular approaches for estimating bare soil surface parameters from RADARSAT-1. Hydrology and Earth System Sciences, 14(11), pp. 2355-2366.

Srivastava , H.S., Patel, P. \& Navalgund, R.R., 2006. How far SAR has fulfilled its expectation for soil moisture retrieval? Microwave Remote Sensing of Atmosphere and Environment-II, AE107, Asia Pacific Remote Sensing Symposium, Goa, India. SPIE Digital Library, Vol. 6410, Paper No. 641001, pp. 1-12. (13-17 Nov, 2006)

Srivastava, H. S., Patel, P., Navalgund, R. R. \& Sharma, Y., 2008. Retrieval of surface roughness using multi-polarized Envisat-1 ASAR data. Geocarto International, 23(1), pp. 6777 .

Topp, G. C., Davis, J. L., \& Annan, A. P. 1980. Electromagnetic determination of soil water content: Measurements in coaxial transmission lines. Water Resources Research, 16(3), pp. 574-582.

Ulaby F.T, Batlivala P.P, Dobson, M.C.1978. Microwave backscatter dependence on surface roughness, soil moisture and soil texture: Part I: bare soil. IEEE Transaction on Geoscience and Remote Sensing. 16, pp. 286-295. 